\title{
O DIREITO FUNDAMENTAL À PROTEÇÃo EM FACE À AUTOMAÇÃo E A INDÚSTRIA 4.0
}

\author{
LUCIANA DE ABOIM MACHADO ${ }^{1}$
}

PRISCILA CAVALCANTI CÔRTES ${ }^{2}$

\section{RESUMO}

Este artigo pretende analisar de que forma a modernidade tem afetado os Direitos fundamentais trabalhistas, especialmente tomando como referência o direito previsto no art. $7^{\circ}, \mathrm{XXVII}$ da Constituição da República Federativa do Brasil. O estudo examinará o impacto da chamada "Indústria 4.0" nas relações laborais e almeja entender como vencer o desafio de equilibrar a inevitável chegada das novidades tecnológicas na sociedade globalizada com a imprescindível proteção dos trabalhadores, a partir de detalhada revisão bibliográfica. Espera-se que a resposta perpasse pela constitucionalização do Direito do Trabalho, a fim de superar esse aparente impasse social e jurídico.

Palavras-chaves: Direito do Trabalho; Proteção em face da automação; Indústria 4.0; Constitucionalização do Direito do Trabalho.

\section{Abstract}

This article aims to analyze how modernity has affected fundamental labor rights, especially with reference to the right provided for in art. 7, XXVII of the Constitution of the Federative Republic of Brazil. The study will examine the impact of the so-called "Industry 4.0" on labor relations and aims to understand how to overcome the challenge of balancing the inevitable arrival of technological innovations in the globalized society with the essential protection of

\footnotetext{
1 Doutora em Direito (USP). Pós-doutora em Direito (UFBA e Università Degli Studi G. d'Annunzio/Itália). Mestre em Direito pela PUC/SP. Coordenadora do Programa de Pós-Graduação Stricto Sensu em Direito e Professora Associada da UFS. Vice-presidente da Asociación Iberoamericana de Derecho del Trabajo y de la Seguridad Social Guillermo Cabanellas. Consultora da Ergon Associates (London). Líder do Grupo de Pesquisa Eficácia dos Direitos Humanos e Fundamentais: seus reflexos nas relações sociais (GEDH/UFS/CNPq). E-mail: lucianags.adv@uol.com.br;

${ }^{2}$ Servidora Pública Federal. Mestranda pela UNIVERSIDADE FEDERAL DE SERGIPE. Pós graduada em Direito e Processo do Trabalho pela Faculdade Estácio de Sá e em Direitos Humanos e Ressocialização pela Faculdade Única.E-mail: pri_cav@hotmail.com
} 
workers, based on a detailed bibliographic review. The answer is expected to perpetuate the constitutionalization of Labor Law, in order to overcome this apparent social and legal impasse.

Keywords: Labor law; Protection due to automation; Industry 4.0; Constitutionalization of Labor Law.

\section{INTRODUÇÃO}

A automação é um fenômeno do mundo contemporâneo, consequência inevitável e irrefreável da modernidade, que atinge a todos os países do globo em virtude da conhecida globalização.

A Constituição da República Federativa do Brasil, já em 1988, trouxe em seu bojo a preocupação, naquele momento ainda incipiente, com forma com que a automação iria atingir as relações de trabalho e os postos de emprego, de modo a não se perder de vista os valores sociais do trabalho, pilar do Estado Democrático de Direito.

Os valores sociais do trabalho e da livre iniciativa juntamente com a dignidade da pessoa humana e a cidadania são fundamentos do nosso Estado Democrático de Direito. Dessa maneira, o intérprete e aplicador da Constituição deve sempre ter em mente a posição privilegiada desses três conceitos ao analisar qualquer situação real a este posta.

Não poderia ser diferente no Direito do Trabalho moderno. Este artigo irá primeiramente analisar os conceitos originados na Alemanha da "Indústria 4.0" e os reflexos deste no direito laboral brasileiro, sem perder de vista o plexo axiológico acima apontado pelo referencial teórico.

Fazendo-se uma análise sobre todos os períodos de exceção que a democracia brasileira sofreu, chega-se à conclusão de que apenas na Constituição Cidadã de 1988 é que os direitos trabalhistas encontra-se topograficamente dentro dos "Direitos e Garantias Fundamentais". Este fato não é aleatório nem uma mera constatação geográfica, mas antes denota a escolha expressa do constituinte pátrio pela proteção desse direito social elevado a uma garantia fundamental do trabalhador, dentro de um Estado Democrático de Direito, rompendo o paradigma autoritário que se arrastava intercaladamente pelo último século.

Nesse ínterim é que se nota a paulatina inserção do Direito do Trabalho no contexto constitucional, com ampliação das garantias e aprofundamento dos direitos sociais dos trabalhadores.

Dentre os direitos previstos, encontra-se o de ser protegido em face à automação (art. $7^{\circ}$, XXVII, CRFB). À época da promulgação da Lei Maior de 1988, a automação brasileira 
ainda era incipiente; o constituinte quando da elaboração das normas constitucionais estava inserido em um contexto de parca industrialização e embrionária utilização de automação nos processos produtivos brasileiros, não tendo, por conseguinte, como prever os avanços tecnológicos por que o Brasil passaria nos anos seguintes a partir da década de 90.

O constituinte se preocupou em destrinchar diversas garantias ao trabalhador, na tentativa de se antecipar às discussões e conflitos que surgiriam no dia a dia dentro da empresa, chegando a prever proteção do empregado em face à automação.

Esse estudo irá verificar se a elevação dos direitos laborais, em especial da garantia à proteção em face à automação, ao patamar constitucional, é capaz de se adaptar à realidade tecnológica experimentada às vésperas da terceira década do terceiro milênio.

Iremos analisar também de que forma esse novo perfil de indústria tem modificado as relações de trabalho e os impactos sociais dentro e fora das empresas, bem como seus reflexos sociais com o desemprego estrutural.

Em seguida será feito estudo acerca da concretização dos direitos fundamentais dos trabalhadores a partir do fenômeno da constitucionalização desta seara privada do Direito. O artigo abordará quais os possíveis caminhos para frear o desmedido desemprego estrutural que o Brasil vivencia acima referido, tal como quais as possibilidades de coexistência entre os avanços tecnológicos e os direitos fundamentais dos trabalhadores, de maneira que seja garantida a dignidade da pessoa humana, Fundamento da República, aos empregados na busca pela sua sobrevivência, sem que haja um retrocesso social tecnológico no país.

Com efeito, busca-se neste estudo compreender os impactos da Quarta Revolução Industrial sobre o Direito do Trabalho e, em especial, sobre o desemprego estrutural, para se analisar quais as possíveis alternativas para a solução desse problema. A principal hipótese a ser testada é se a Constitucionalização do Direito do Trabalho pode ser um caminho alternativo para essa solução, especialmente considerando o Direito Fundamental previsto no art. $7^{\circ}$, XXVII, CRFB de proteção do trabalhador em face à automação.

\section{REFLEXOS DA NOVA INDÚSTRIA 4.0 NO DIREITO DO TRABALHO}

Os paradigmas estabelecidos na década de 40 no Brasil, onde se gestou a Consolidação das Leis Trabalhistas foram se alterando ao longo das décadas. Hoje, quase oitenta anos depois, praticamente não se encontram mais os mesmos tipos de relação trabalhista. A própria subordinação clássica está cada vez mais rara de ser constatada, pois levavam em consideração 
um panorama trabalhista que se desenrolava em imensos pátios de fábrica com inúmeros funcionários, cada um direcionado para cumprir exclusivamente sua única função ${ }^{3}$.

Juntamente com o avanço dos anos, a era digital adentrou o campo laboral impactando e modificando a forma de se enxergar os vínculos trabalhistas, as formas de prestação de serviço, de controle e exercício dos poderes pelo empregador, a maneira de se relacionar com o cliente e de auferir lucros.

Inclusive autores sugerem que (SANTOS, 2019, p. 20), considerando todo esse novo quadro, estaríamos vivenciando a chamada $4^{\mathrm{a}}$ Revolução Industrial, com a perspectiva de uma indústria 4.0, representando as recentes maneiras de labor ante as inovações trazidas pela tecnologia, a exemplo do teletrabalho, "home office", com possibilidade de gerenciamento e produção online em qualquer parte do mundo.

No que diz respeito à origem do termo "Indústria 4.0", aponta-se (GRAGLIA, 2018, p. 114) que este teve seu embrião na Alemanha com a feira industrial Hannover $\mathrm{Messe}^{4}$ de 2012 que ocorre anualmente na cidade de Hannover naquele país. O referido termo foi cunhado com o sufixo ". 0 " para remeter à tecnologia e a forma de nomenclatura utilizada na internet que foi importada para a área trabalhista. O número " 4 " diz respeito à $4^{\mathrm{a}}$ revolução industrial que estaríamos vivenciando com instrumentos ciberfísicos que adentraram nos meios de produção e de trabalho. Nesse sentido, aduz Graglia (2018):

A indústria 4.0 é uma nova configuração do sistema manufatureiro, fortemente baseada na tecnologia e na interligação entre as dimensões física e virtual, o chamado ciberespaço. Esta interligação, ou fusão, é tornada possível pelo uso de sistemas ciberfísicos.

Cumpre destacar que os princípios da Indústria 4.0, segundo Kagermann et al. (2013), estariam resumidos em Interoperabilidade, Virtualização, Descentralização, Capacidade em tempo real, Orientação a serviço, Modularidade.

Nesse ínterim, Graglia (2018) define a Interoperabilidade como um facilitador imprescindível para a viabilização da moderna indústria 4.0, uma vez que neste cenário a comunicação constante entre os responsáveis pelo sistema é de suma importância para o desenvolvimento da gestão dos processos. Analisaremos abaixo as definições dos principais termos a partir dos conceitos trazidos pelo referido autor.

Quanto à "Virtualização", o mesmo autor define, como a instalação de sensores que compilam todas as informações disponíveis nos processos realizados na empresa ou fábrica.

\footnotetext{
${ }^{3}$ Como bem ilustrado no filme Tempos Modernos de Charles Chaplin, 1936.

4 Informações podem ser obtidas no sítio eletrônico da feira: 
Será necessária, portanto, a contratação e capacitação de funcionários habilitados e compreender e interpretar os dados extraídos.

No tocante à "Descentralização", o doutrinador entende que é o princípio segundo o qual o gestor estabelece critérios específicos para que as máquinas passem a fornecer os dados de seu ciclo de trabalho. A partir de tais informações, consegue-se ter consciência real de todos os custos, da ociosidade, da capacidade dentre outros.

Já no que diz respeito à "Capacidade em tempo real" é a possibilidade de acompanhamento da produção da empresa ou fábrica em tempo real.

Por seu turno, o princípio da "Orientação a serviço" diz respeito ao conceito para os softwares a fim de padronizar os métodos e processos específicos utilizados, para que sejam implementadas práticas na empresa a partir dessa orientação.

Por fim, no que tange ao princípio da "Modularidade", refere-se ao planejamento da manufatura empresarial em módulos a fim de que haja uma perspectiva da demanda necessária de produção. Assim, há uma adaptação de forma flexível às alterações eventuais de requisitos com substituição ou mesmo expansão dos módulos iniciais.

Pode se afirmar, por outro lado, segundo Graglia (2018, p. 128) que são características da Indústria 4.0:

\begin{abstract}
Redes verticais de sistemas inteligentes de produção, em fábricas inteligentes, produzindo produtos inteligentes (...), associadas a redes de logística inteligente, marketing e serviços inteligentes (...). Integração horizontal das cadeias de suprimentos por meio de uma nova geração de redes globais de criação de valor e novos modelos comerciais e de cooperação em países e continentes (BAUER, 2015). Gerenciamento de todo o ciclo de vida do produto.
\end{abstract}

Esses conceitos citados afetam inevitavelmente o campo do trabalho, especialmente considerando a proteção concedida no bojo do art. $7^{\circ}, \mathrm{XXVI} \mathrm{CRFB}^{5}$ aos trabalhadores em face da automação, constituindo-se num direito e garantia fundamental do indivíduo.

É importante registrar que à época da promulgação da Lei Maior de 1988, a automação brasileira ainda era incipiente:

Durante toda a década de 80 , não ocorreram significativas mudanças na cadeia
produtiva. (...) Mas o problema da competitividade do setor não estava apenas nos
seus fornecedores - a própria indústria de máquinas-ferramenta demonstrava grandes
defasagens tecnológicas em seus processos produtivos. Vários trabalhos recentes
sobre o setor de máquinas-ferramenta apontaram para o hiato tecnológico do setor
em termos de processo; os principais problemas estavam localizados sobretudo no
baixo índice de automação, tanto de projeto quanto de fabricação. Além do baixo
número de equipamentos automatizados, a grande maioria das empresas os utilizava

5 “Art. $7^{\circ}$ São direitos dos trabalhadores urbanos e rurais, além de outros que visem à melhoria de sua condição social:

(...)

XXVII - proteção em face da automação, na forma da lei;" 
de forma não integrada. Assim, a defasagem tecnológica de processo do setor de máquinas-ferramenta e os problemas com sua base de fornecedores não permitiram melhorar significativamente a competitividade externa do setor. (VERMULM, 1996, p. 52).

Ressalte-se que a realidade hodierna é outra e o que se defende nesse dispositivo constitucional não implica que o legislador constituinte deseje impedir que o avanço tecnológico influencie o meio ambiente do trabalho, uma vez que este é um fato e uma tendência em um mundo cada vez mais digital e globalizado.

A maneira como o inciso em questão restou redigido dá a falsa impressão de que a automação é um mal que precisa ser combatido pelo Direito (GONÇALVES, 2003, p. 164) . Hoje, contudo, tem-se a certeza de que a $4^{a}$ revolução industrial é uma realidade necessária e a sua intromissão nas relações do trabalho é inevitável.

Não se olvide que o mesmo constituinte também previu o direito à livre iniciativa (art. $1^{\circ}$, IV, CRFB) e o incentivo ao desenvolvimento tecnológico (art. 218, CRFB), de modo que a proteção do trabalhador em face à automação não pode se constituir um empecilho ao desenvolvimento das empresas e da tecnologia.

A automação experimentada com a nova indústria 4.0 impacta diretamente os postos de trabalho. A exigência é cada vez maior por profissionais qualificados nas áreas tecnológicas, com expertise em sistemas e gestão de dados, em detrimento da grande mão de obra desprovida de qualificação técnica que é a massiva parte do contingente de desempregados no país ${ }^{6}$.

Ou seja, além da dificuldade comum que a sociedade moderna está enfrentando na geração de novos postos de emprego, também há o desafio para os trabalhadores sem acesso a profunda escolarização que não conseguem se enquadrar em funções que demandam um conhecimento técnico especializado que não lhes foi ofertado.

Ademais, existe igualmente a problemática da substituição de uma boa quantidade de trabalhadores por apenas 1 (uma) máquina, considerando que a tecnologia disponível permite que apenas um equipamento substitua o trabalho que antes seria desempenhado por um conjunto de pessoas ${ }^{7}$, sem pausas e numa velocidade bastante superior. Tudo isso sem gerar custos trabalhistas.

Esses fatores ocasionam o chamado desemprego estrutural, já que suprime a necessidade da existência de níveis inteiros de empregos e funções, substituindo os postos de

\footnotetext{
${ }^{6}$ Nesse sentido, confira-se notícia no sítio eletrônico: https://exame.abril.com.br/economia/brasileirodesempregado-sem-formacao-nao-consegue-nem-trabalhos-basicos/

7 Consoante notícia disponível no sítio eletrônico: https://www.uol/tecnologia/especiais/inteligenciaartificial-vai-acabar-com-empregos-.htm\#tematico-1
} 
serviço e vitimando o ser humano dada a maciça utilização da tecnologia (SANTOS, 2005, p. $145)$.

Relatório realizado pela consultoria McKinsey Global Institute ${ }^{8}$ conclui que a automatização afetará entre 400 e 800 milhões de pessoas em todo o mundo até 2030. Em países tecnologicamente mais desenvolvidos como Estados Unidos da América e Alemanha, até um terço da força de trabalho atualmente disponível precisará aprender novas habilidades a fim de encontrar postos de emprego. $\mathrm{O}$ estudo ainda conclui que trabalhadores com menos estudos serão mais fortemente afetados por esse processo de automatização.

Ou seja, encontra-se à frente do operador do Direito o grande desafio de construir um modelo de desenvolvimento tecnológico e social que ao mesmo tempo não seja excludente em relação àqueles marginalizados economicamente, sem deixar de encarar a realidade da Indústria 4.0, demandando uma reorganização do trabalho.

Essas forças se mostram antagônicas, uma vez que o progresso tecnológico que visa a ampliação das margens de lucro foi construída historicamente através da precarização das condições de vida dos trabalhadores, com a corrosão de seus direitos fundamentais e acirramento das tensões sociais a partir da crescente desigualdade. (SANTOS; SOARES, 2015, p.3).

Essa tensão foi descrita por Castel (2005, p. 35):

Estamos sem dúvida, diante de uma bifurcação: aceitar uma sociedade inteiramente submetida às exigências da economia ou construir uma figura do Estado social a altura dos novos desafios. A aceitação da primeira parte da alternativa não pode ser excluída. Mas poderia custar o desmoronamento da sociedade salarial, isto é, desta montagem inédita de trabalho e de proteções que teve tanta dificuldade para se impor

Assim, para se alcançar o equilíbrio entre forças aparentemente antagônicas, o caminho a ser adotado é a constitucionalização do trabalho, a qual permite uma reflexão quanto à necessária coexistência entre os avanços tecnológicos do Século XXI, gerados pela pela Indústria 4.0, e a garantia de postos de trabalho decentes que concretizem a dignidade da pessoa humana do trabalhador.

\section{A CONSTItUCIONAlizaÇÃO DO DIREITO DO TRABAlHO PARA GARANTIR A EFICÁCIA DOS DIREITOS DOS TRABALHADORES}

A dogmática constitucional deve tomar como referência primordial a supremacia que a Constituição Federal ocupa no Ordenamento Jurídico brasileiro, bem como em outros Estados

8 Informações podem ser obtidas a partir da reportagem disponível no sítio eletrônico: http://www.ihu.unisinos.br/186-noticias/noticias-2017/574292-robotica-eliminara-ate-800-milhoes-de-empregosate-2030 
Constitucionais ocidentais. A hermenêutica deve partir do princípio que o Poder emana do povo $^{9}$, o qual escolheu seus representantes democraticamente para promulgação de uma Constituição que acolha todos os anseios sociais e Direitos Fundamentais básicos para a concretização de uma vida com dignidade.

Estes detalhes essenciais presentes em uma Constituição foram assim abordados por Canotilho (2001, p.1.131):

\begin{abstract}
A Constituição é uma lei dotada de características especiais. Tem um brilho autônomo expresso através da forma, do procedimento de criação e da posição hierárquica das suas normas. Estes elementos permitem distingui-la de outros actos com valor legislativo presentes na ordem jurídica. Em primeiro lugar, caracteriza-se pela sua posição hierárquico-normativa superior relativamente às outras normas do ordenamento jurídico. [...] a superioridade hierárquico-normativa apresenta três expressões. 1) as normas constitucionais constituem uma lex superior que recolhe o fundamento da validade um si própria (autoprimazia normativa); (2) as normas de constituição são normas de normas (normae normarum) afirmando-se como uma fonte de produção jurídica de outras normas (leis, regulamentos, estatutos); (3) a superioridade normativa das normas constitucionais implica o princípio da conformidade de todos os actos dos poderes públicos com a Constituição.
\end{abstract}

Com efeito, a Constituição serve de alicerce para todos os interesses sociais, fixando procedimentos estruturantes para a solução dos conflitos iminentes no seio das relações interpessoais, determinando o direcionamento a ser seguido tanto pelos operadores do Direito quanto pelos legisladores em sua função essencial.

Deve-se levar em conta que a rigidez da Constituição Federal brasileira, faz com que esta represente o mais elevado ponto dentro da pirâmide normativa da ordem jurídica interna, de onde partem todos os raciocínios jurídicos e onde todas as normas (regras e princípios) encontram fundamento para sua existência. Sob o ponto de vista jurídico, portanto, as normas constitucionais exigem um procedimento específico e mais complexo para sua alteração, com vistas a manutenção da segurança da estrutura piramidal do ordenamento.

Nesse viés, Kelsen (1998, p. 188) assim ensina:

\begin{abstract}
A afirmação de que uma lei válida é "contrária à Constituição" (anticonstitucional) é uma contradictio inadjecto; pois uma lei somente pode ser válida com fundamento na Constituição. Quando se tem fundamento para aceitar a validade de uma lei, o fundamento da sua validade tem de residir na Constituição. De uma lei inválida não se pode, porém, afirmar que ela é contrária à Constituição, pois uma lei inválida não é sequer uma lei, porque não é juridicamente existente e, portanto, não é possível acerca dela qualquer afirmação jurídica.
\end{abstract}

Desse modo, pode-se concluir que as normas constitucionais são supremas, não encontrando dentro do ordenamento jurídico interno outras que lhes sejam hierarquicamente

9 art. $1^{\circ}$ Parágrafo único. Todo o poder emana do povo, que o exerce por meio de representantes eleitos ou diretamente, nos termos desta Constituição. 
superiores, caracterizando-se, conforme apontado por Kelsen, como parâmetro de validade para todas as demais normas existentes.

Alcança conclusão semelhante, Canotilho (2001, p. 135) quando entende estar a Constituição no ápice da estrutura normativa. É dele a afirmação de que:

\begin{abstract}
A lógica é a lógica da pirâmide geométrica. A ordem jurídica estrutura-se em termos verticais, de forma escalonada, situando-se a constituição no vértice da pirâmide. Em virtude desta posição hierárquica ela actua como fonte de outras normas. No seu conjunto, a ordem jurídica é uma "derivação normativa" a partir da norma hierarquicamente superior, mesmo que se admita alguns espaços criados às instâncias hierarquicamente inferiores quando concretizam as normas superiores.
\end{abstract}

A partir do fenômeno da descodificação, paulatinamente os institutos mesmo do Direito Privado, passaram a ser relegados para o Direito Constitucional, sendo inseridos no texto da Constituição por meio de normas de conteúdo programático, tais como aqueles previstos no seu Título II de "Direitos e Garantias Fundamentais".

O constitucionalismo no mundo ocidental, de forma geral chega ao novo milênio renovado e com posição de destaque após sobreviver como alternativa aos regimes que disputaram prevalência, consagrando-se como alternativa após duas grandes guerras e revoluções liberais.

Seu êxito pode ser atribuído majoritariamente aos conceitos de legitimidade popular na defesa da vontade nacional por meio do poder constituinte democraticamente escolhido, de limitação do poder a partir da repartição das competências, com observância igualmente dos direitos das minorias e não menos importante da incorporação ao texto constitucional dos valores materiais de conquistas sociais, políticas e éticas (BARROSO, 2001, p. 11-12).

Efetivamente, a Constituição Federal de 88 rompeu com os paradigmas até então sustentados pelas Constituições anteriores e ampliou consideravelmente o abrigo aos Direitos Fundamentais em seu bojo, definindo inclusive princípios básicos para as relações laborais.

O Direito individual do Trabalho tem caráter majoritariamente privado, classificação que se tornou ainda mais evidente após a chamada "reforma trabalhista", Lei n 13.467/17, a qual trouxe ampliação da autonomia das partes para formular regras para o contrato.

O desequilíbrio entre as partes contratuais, no entanto, é evidente, sendo premente a aplicação de Direitos Fundamentais de forma verticalizada. Assim, traz a Constituição em seu bojo direitos trabalhistas para garantir um patamar mínimo civilizatório para os empregados, tais como aqueles inscritos nos arts. $7^{\circ}$ e $8^{\circ}$.

Tais garantias constitucionais aqui retratadas é que impuseram um freio ao descompasso legislativo na ânsia de flexibilizar as regras trabalhistas, trouxe grande precarização às relações laborais, consoante afirmado em tópico anterior. 
O fenômeno do deslocamento do epicentro jurídico do Direito do Trabalho, anteriormente focado nas regras de Direito Privado para o bojo Constitucional tem importância muito mais do que meramente topográfica. É um processo que alterou sensivelmente a forma de se estudar e de se aplicar o Direito laboral e suas instituições, revisando seus princípios e regras que o estruturam.

Com efeito, as normas trabalhistas, em especial as inseridas na Consolidação das Leis do Trabalho, promulgada numa fase de exceção à regra democrática no Brasil, devem ser interpretadas sob o referencial sempre constitucional. Ademais, as alterações normativas posteriores à Lei Maior de 1988 também devem ter como referencial constante as garantias constitucionais. Ensina Beatriz Cardoso Montanhana:

A Consolidação das Leis do Trabalho deve ser interpretada, portanto, sob o referencial constitucional. Além disso, as alterações normativas também não podem se afastar desse referencial. Se o legislador, seja ele autônomo ou heterônomo, identificar o trabalho como um fator de produção, as normas não se fundamentarão sobre valores essenciais ao ser humano. (MONTANHANA, 2011, p. 32)

Dentre as inúmeras esferas de direitos do trabalhador que o legislador constituinte buscou antecipar e prever na Lei Maior, encontra-se a incipiente, à época, discussão sobre a perda de empregos para as máquinas, realidade que se acentuou intensamente no decorrer das décadas.

A globalização como fenômeno mundial reestruturante do capitalismo sob regência do pensamento neoliberal trouxe reformas sociais inevitáveis. Os avanços tecnológicos vêm nesse bojo com implementação de mudanças dentro do meio ambiente de trabalho, contribuindo para sua precarização e, por outro lado, ampliando os lucros. (SANTOS; SOARES, 2015, p. 2).

Assim, no que diz respeito à temática da proteção em face à automação, o fenômeno da constitucionalização do Direito do Trabalho recebeu maior destaque a partir do art. $7^{\circ}$, XXVII, CRFB, que tratou expressamente do direito fundamental do trabalhador de ser resguardado em decorrência dessa realidade.

Este inciso teve particular inspiração na Declaração Universal dos Direitos Humanos de 1948, o qual, em seu artigo XXIII previa que "toda pessoa tem direito ao trabalho, à livre escolha de emprego, a condições justas e favoráveis de trabalho e à proteção contra o desemprego" (Assembleia Geral da ONU, 1948). Ou seja, desde a metade do século passado a proteção contra o desemprego já é fator decisivo nas normas internacionais definidas pelo sistema onusiano.

Tendo em vista que o processo de industrialização do Brasil foi deveras tardio, como apontado no tópico introdutório deste estudo, o Constituinte que antecedeu o de 1988 não 
esboçou preocupação quanto ao desemprego estrutural ocasionado pela modernização das relações de trabalho e pelo impacto da tecnologia dentro das empresas. Foi unicamente na Subcomissão de Ciência e Tecnologia da Constituinte de 88 que surgem no Brasil as discussões a respeito dos reflexos da automação no campo do trabalho (MARTINS, 2000, p. 262).

O desemprego estrutural enquanto um problema sistemático pode encontrar um caminho a partir da constitucionalização do Direito do Trabalho na medida em que, com a sobrelevação desta seara do Direito ao âmbito Constitucional, há também valorização do patamar dos direitos sociais relativos ao contrato de trabalho, o que leva a uma maior proteção do trabalhador atingido pelas medidas.

É nesta toada que a proteção inserida no inciso XXVII da Lei Maior, garantindo o direito fundamental ao trabalho mesmo em face às novas tecnologias, dentro do contexto da indústria 4.0, traz relevância constitucional ao Direito Laboral, reforçando propositalmente o direito social e fundamental ao trabalho em si (art. $6^{\circ}$, "caput", CRFB).

Destaque-se que essa garantia não deve ser vista como um empecilho às inovações tecnológicas, mas sim como um chamado do constituinte para que o aplicador do Direito busque soluções para que a automação coexista em harmonia com os direitos do trabalhador. Nas palavras da Min. Cármen Lúcia, ao relatar o Mandado de Injunção nº 618-MG:

$\mathrm{O}$ art. $7^{\circ}$, inc. XXVII, da Constituição não estipula como direito do trabalhador proteção contra "inovações tecnológicas", mas sim "em face da automação", conceitos diferentes. Na automação substitui-se o trabalho humano pelo de máquinas. A inovação tecnológica está relacionada a mudanças na tecnologia, não havendo necessariamente a substituição do homem por máquina.

É preciso notar, no entanto, que a proteção em face à automação está inserida num dispositivo de eficácia limitada ${ }^{10}$, uma vez que relega a regulamentação do referido direito ao legislador ordinário, o qual, até o presente momento, queda-se inerte.

A inércia do legislador em 30 anos de promulgação da Constituição representa um inegável déficit democrático pois impossibilita a concretização dos planos criados para a sociedade pelos legítimos representantes constituintes desta.

Tratando a respeito das normas de eficácia limitada, Octávio Bueno Magano pontua que mesmo não possuindo a mesma aplicabilidade das normas de eficácia plena e mesmo contida, as normas limitadas ainda assim possuem uma certa eficácia vertical negativa no sentido de impedir a produção de normas nas esferas inferiores que sejam contrárias àquela prevista na Constituição. Assim dispõe o autor:

\footnotetext{
${ }^{10}$ Classificação adotada por José Afonso da Silva, que entende classificarem-se as normas constitucionais de acordo com sua aplicabilidade em eficácia plena, contida e limitada, sendo estas últimas aquelas que dependem de regulamentação por parte do legislador ordinário por escolha expressa do constituinte (SILVA, 2001).
} 
Não significa com isso dizer que se trate de normas meramente declaratórias, porque possuem força vinculatória invalidante de qualquer medida que lhes seja contrária. Além disso, vinculam diretamente o legislador que, não tomando medidas necessárias para as tornar efetivas, poderá incorrer em inconstitucionalidade por omissão. (MAGANO, 1992, pp. 270-271).

Essa eficácia negativa também atinge os particulares de forma horizontal, vinculando estes em todas as relações, inclusive a trabalhista, de modo que não é possível que entre particulares se atue de forma contrária ao previsto em normas constitucionais, independente de qual a amplitude da eficácia (ALVES, 2011).

Outrossim, as normas que preveem direitos fundamentais têm sua aplicabilidade imediata prevista no art. $5^{\circ}, \S^{\circ}, \mathrm{CRFB}^{11}$.

Nesse esteio, podemos perceber que se faz necessário o investimento em qualificação dos trabalhadores para que estes estejam preparados para a nova realidade que já nos alcançou. Esse investimento deve partir, portanto, não apenas do Governo no intento de concretizar a garantia prevista no art. $7^{\circ}, \mathrm{XXVII}$ aqui discutido, mas também por parte dos empregadores como forma de cumprimento da função social da empresa.

Tais fundamentos, portanto, reforçam a razão pela qual a Constitucionalização dos Direitos trabalhistas são um caminho para que os empregadores sejam vinculados a observar o Direito Fundamental do trabalhador de não ser simplesmente descartado em virtude das novas tecnologias que surgem com a indústria 4.0.

A característica da dignidade que distingue o ser humano que trabalha de uma simples máquina, no entanto não pode ser tida como um obstáculo aos avanços da livre iniciativa, uma vez que esta deve se dar de forma a contemplar a responsabilidade empresarial com a sua função

\footnotetext{
11 TÍTULO II
}

\section{Dos Direitos e Garantias Fundamentais}

\section{CAPÍTULO I}

DOS DIREITOS E DEVERES INDIVIDUAIS E COLETIVOS

Art. $5^{\circ}$ Todos são iguais perante a lei, sem distinção de qualquer natureza, garantindo-se aos brasileiros e aos estrangeiros residentes no País a inviolabilidade do direito à vida, à liberdade, à igualdade, à segurança e à propriedade, nos termos seguintes:

(...)

$\S 1^{\circ}$ As normas definidoras dos direitos e garantias fundamentais têm aplicação imediata. [grifos 
social (art. 170, III, CRFB ${ }^{12}$ ) e com a dignidade da pessoa humana do trabalhador (art. $1^{\circ}$, III, $\mathrm{CRFB}^{13}$ ) acima destacada, fundamento da República Federativa do Brasil.

\section{CONCLUSÃO}

O avanço tecnológico testemunhado mais fortemente nas últimas décadas tem trazido impactos inegáveis às relações laborais. O crescente desenvolvimento da era digital no mundo moderno é aquilo que se cunhou de Quarta Revolução Industrial, ou Indústria 4.0, estando fundamentada nos princípios discutidos ao longo desse estudo.

Não cabe ao Direito do Trabalho possuir uma ilusão "quixotesca" de que há alguma solução mágica que segurará esse influxo tecnológico de inserção das máquinas na produção tomando espaços antes ocupados exclusivamente por seres humanos.

Por outro lado, isso de maneira alguma significa abandonar o Princípio norteador de todo o Direito Laboral, o Princípio da Proteção do Trabalhador ${ }^{14}$.

A resposta para a garantia da dignidade da pessoa humana do trabalhador mesmo num mundo digital perpassa pela constitucionalização do Direito do Trabalho, elevando os direitos sociais trabalhistas do empregado à classe de Direitos Fundamentais.

Trata-se, em especial, do art. $7^{\circ}, \mathrm{XXVI}, \mathrm{CRFB}$ que vai garantir a eficácia do Princípio protetivo em face à automação. Para se atingir esse objetivo é preciso adotar a corrente doutrinária que enxerga a possibilidade de vinculação horizontal negativa dos direitos fundamentais mesmo que previstos em normas de eficácia limitada.

Não é absolutamente devida a estigmatização das tecnologias trazidas no bojo da indústria 4.0, uma vez que além de inevitáveis, estas se revelam imprescindíveis para o desenvolvimento humano. O que propõe é que estas sejam utilizadas de forma concomitante ao oferecimento de oportunidades de subsistência ao trabalhador e de forma a gerar qualidade de vida a toda a sociedade.

12 “Art. 170. A ordem econômica, fundada na valorização do trabalho humano e na livre iniciativa, tem por fim assegurar a todos existência digna, conforme os ditames da justiça social, observados os seguintes princípios:

(...)

III - função social da propriedade;” (grifo nosso)

13 “Art. $1^{\circ}$ A República Federativa do Brasil, formada pela união indissolúvel dos Estados e Municípios e do Distrito Federal, constitui-se em Estado Democrático de Direito e tem como fundamentos:

(...)

III - a dignidade da pessoa humana;”

14 Segundo Américo Plá Rodriguez (2000, p. 152), este princípio é a própria razão de ser do Direito do Trabalho. 
A automação, portanto, deve ser implementada de maneira razoável e planejada de modo que não produza consequências negativas na vida do trabalhador, em especial no que diz respeito ao desemprego estrutural que atinge duramente a sobrevivência do empregado.

Para atingir tais objetivos é necessário que haja especialmente um investimento em promoção de difusão de conhecimento com ofertas de cursos para qualificação técnica dos indivíduos para que estes estejam preparados para lidar com as novas realidades no ambiente de trabalho.

Com a maior oferta de treinamento, os trabalhadores serão realocados em novas profissões que surgem a todo instante, ocupando postos de trabalho que controlem e que cooperem com as máquinas.

Ou seja, se houve melhora no número de cursos de aprimoramento oferecidos aos trabalhadores, estes poderão alcançar sua recolocação no mercado de trabalho em outras funções mais modernas e atuais, inclusive envolvidas na criação e operacionalização das máquinas.

Essa capacitação, portanto, é vital para o aproveitamento dos empregados nas novas demandas que nascem com o desenvolvimento de novas tecnologias.

A promoção de cursos, destaque-se, deve partir não apenas do Estado, mas também e especialmente dos empregadores, cumprindo com a função social da sua propriedade e da empresa, além de que gerará benefício e lucro para o estabelecimento a geração de mão de obra mais qualificada produzindo.

A política de proteção do trabalhador em face à automação, portanto, não pode perder de vista o caráter necessariamente humanístico que não implica em empecilho para o desenvolvimento científico e ampliação das tecnologias dentro da empresa.

Assim, o aplicador do Direito deve buscar incidir a garantia do trabalhador de forma que coexista de maneira harmoniosa com as outras previsões do constituinte, salvaguardando a dignidade do ser humano que necessita do trabalho para a própria subsistência, mas também o exercício da livre iniciativa, protegido pela Constituição.

Desse modo, consegue-se evitar o desemprego estrutural sem, por outro lado, deixar as relações laborais em descompasso com a realidade, visando apenas a uma proteção esvaziada do trabalhador. Ao trabalhador não basta a garantia de emprego, deve haver um emprego digno e decente. E, por outro lado, para a garantia de emprego não bastam medidas formais de proteção da dispensa e limitação do poder do empregador.

Consequentemente, a Constitucionalização do Direito do Trabalho tem cumprido papel importante ao mover o epicentro das normas laborais que antes eram majoritariamente 
com viés privatista, para uma análise a partir dos princípios fundamentais constitucionais, neles inserido a proteção do trabalhador em face à automação. Faz-se necessário, pois, que não se perca de vista a modernização trazida pela Indústria 4.0, mas que esta esteja acompanhada de medidas que possibilitem a qualificação do trabalhador a fim que de o desemprego estrutural gerado seja combatido com postos de trabalho decentes.

\section{REFERÊNCIAS}

ALVES, Henrique Fonseca. Proteção em face da automação e a eficácia dos direitos fundamentais. Sapientia - Revista de Direito do Centro Universitário Estácio de Sá de Belo Horizonte. Minas Gerais, vol. 1, n. 1, 2011. Não paginado. Disponível em: http://revistaadmmade.estacio.br/index.php/direitobh/article/viewFile/259/164. Acesso em: 29/10/2019.

ASSEMBLEIA GERAL DA ONU. Declaração Universal dos Direitos Humanos. Nações Unidas, 1948, Paris, art. XXIII. Disponível em: http://www.un.org/en/universal-declarationhuman-rights/. Acessado em: 6 de outubro de 2019.

BARROSO, Luis Roberto. Fundamentos teóricos e filosóficos do novo direito constitucional brasileiro : (pós-modernidade, teoria crítica e pós-positivismo). Interesse público, v. 3, n. 11, p. 42-73, jul. 2001.

BRASIL. Constituição (1824). Constituição Política do Império do Brazil. Rio de Janeiro, 1824. Disponível em: http://www.planalto.gov.br/ccivil_03/constituicao/constituicao24.htm. Acesso em: 29/10/2019.

BRASIL. Constituição (1988). Constituição da República Federativa do Brasil. Brasília, DF: Senado Federal: Centro Gráfico, 1988.

BRASIL. Supremo Tribunal Federal. Mandado de Injunção no 618 MG. Relator: Min. Cármen Lúcia. Brasília, Data de Julgamento: 29/09/2014, Data de Publicação: DJe-192 01/10/2014.

CANOTILHO, J. J. Gomes. Direito Constitucional e teoria da constituição. 2. ed. Coimbra: Almedina, 2001.

CASTEL, Robert. A insegurança social: o que é ser protegido? Petrópolis: Vozes, 2005. COIMBRA, Rodrigo; WITTEKIND, Ellara Valentini. A Constitucionalização do Direito do Trabalho na trilha do Princípio da Dignidade da pessoa humana. in: Revista Quaestio Iuris. vol. 09, $\mathrm{n}^{\circ}$. 03, Rio de Janeiro, 2016. pp. 1645-1669.

GONÇALVES, Rogério Magnus Varela. Direito Constitucional do Trabalho: aspectos controversos da automatização. Porto Alegre: Livraria do Advogado Editora, 2003. 
KAGERMANN, H., WAHLSTER, W., HELBRIG, J. Recommendations for implementing the strategic initiative INDUSTRIE 4.0 Final report of the Industrie 4.0 Working Group [Relatório]. Frankfurt: National Academy of Science Engineering, 2013.

MARTINS, Sérgio Pinto. A continuidade do contrato de Trabalho. Rio de Janeiro: Atlas, 2000.

MONTANHANA, Beatriz Cardoso. Os direitos fundamentais do trabalhador e as estruturas sociais de poder das relações de trabalho: em busca do consenso sobre a dignidade humana. Tese (Doutorado em Direito). Faculdade de Direito, Universidade de São Paulo, São Paulo, 2011.

KELSEN, Hans. Teoria pura do direito. Tradução de João Baptista Machado. $6^{a}$ ed. - São Paulo : Martins Fontes, 1998.

RODRIGUEZ, Américo Plá. Princípios de Direito do Trabalho. 3. ed. atual. São Paulo: LTr, 2000.

SANTOS, Ariane Joice dos. Direito coletivo do trabalho: as relações coletivas de trabalho após o advento da lei da reforma trabalhista (Lei no 13.467/2017). São Paulo: LTr, 2019. SANTOS. Marcus Tullius Leite Fernandes dos Santos. Automatização da produçãa humana e desemprego estrutural. Prima Facie, v. 4, p.135-150, jul./dez., 2005. Disponível em http://periodicos.ufpb.br/ojs/index.php/primafacie/article/view/4565. Acesso em 09 out. 2019.

SANTOS, Rosenjura; SOARES, Érica. O direito à proteção em face da automação e desemprego tecnológico: parâmetros constitucionais para regulamentação. In: $3^{\circ}$ Congresso Internacional de Direito e Contemporaneidade, 2015, Santa Maria, RS. Anais do $3^{\circ}$ Congresso Internacional de Direito e Contemporaneidade.. Disponível em: Www.ufsm.br/congressodireito/anais/2015/6-20.pdf. Acesso em: 29 out. 2019. SILVA, José Afonso da. Aplicabilidade das Normas Constitucionais. 5 Ed. - São Paulo/SP: Malheiros Editores, 2001.

SILVA NETO, Manoel Jorge. Notas Sobre a Eficácia da Norma Constitucional Trabalhista. São Paulo. LTr, 1998.

VAINER, Bruno Zilberman. A força normativa da constituição como garantidora da segurança jurídica: uma análise das obras de Konrad Hesse e de Ferdinand Lassale. Revista Brasileira de Direito Constitucional, $\mathrm{n}^{\mathrm{o}}$ 10-jul/dez.2007.

VERMULM, Roberto. Estratégias empresariais nos anos noventa: o setor de máquinasferramenta. In: Cadernos de Gestão Tecnológica, n. 30. Disponível em:

www.fia.usp.br/pgtusp/. Acesso em: 29 nov. 2019. 
